Part of Journal of Research of the National Bureau of Standards, Volume 25, December 1940

\title{
STANDARD ELECTRODE POTENTIAL OF SODIUM ${ }^{1}$
}

\author{
By Edgar Reynolds Smith and John Keenan Taylor ${ }^{2}$
}

\section{ABSTRACT}

From measurements of the cell $\mathrm{Na}(\mathrm{s}) ; \mathrm{NaI}$ (in dimethylamine); $\mathrm{Na}(0.0651 \%$ amalgam) and the cell $\mathrm{Na}(0.0651 \%$ amalgam $) ; \mathrm{NaCl}(0.05$ or $0.1 \mathrm{~m}), \mathrm{AgCl}(\mathrm{s})$; $\mathrm{Ag}(\mathrm{s})$, the standard electrode potential $\mathrm{Na}(\mathrm{s})$; $\mathrm{Na}^{+}$over the temperature range of $5^{\circ}$ to $40^{\circ} \mathrm{C}$ was obtained with the aid of values of the standard electrode potential of the silver-silver chloride electrode, previously determined by Harned and Ehlers, and of the activity coefficients of solutions of sodium chloride, previously determined at $25^{\circ} \mathrm{C}$ by Brown and MacInnes. The activity coefficients were corrected to the other temperatures by the use of data on heats of dilution determined by Gulbransen and Robinson. The final results were expressed by the equation

$$
E^{\circ}=2.71324+0.0007532(t-25)+0.000000688(t-25)^{2} .
$$

Values of changes in free energy, entropy, and heat content accompanying the reactions corresponding to various combinations of the cells were calculated.

\section{CONTENTS}

I. Introduction

II. Units and standards

III. Materials__._.

IV. Apparatus and procedure

V. Results and discussion _... 741

VI. References__................ 746

\section{INTRODUCTION}

The reaction of the alkali metals with water disturbs the equilibrium conditions necessary for direct measurements of their electrode potentials. An indirect method which overcomes this difficulty depends on the possibility of measuring (a) the potential of a dilute amalgam of the alkali metal with respect to an aqueous solution of its ions and a reference electrode, and (b) the difference in potential between the same amalgam and the pure metal when both are immersed in a nonaqueous conducting solution containing ions of the alkali metal. The nonaqueous solvent must not react with the alkali metal and must dissolve the alkali salt sufficiently to form an electrolytic solution. The success of the amalgam electrode in aqueous solution depends on the lowering of the activity of the metal

\footnotetext{
${ }_{1}^{1}$ Presented before the Division of Physical and Inorganic Chemistry at the 100th Meeting of the American Chemical Society, Detroit, Mich., September 9 to 13, 1940.

${ }_{2}$ This paper contains material from a thesis submitted to the University of Maryland by John Keenan Taylor in partial fulfillment of the requirements for the degree of Doctor of Philosophy. The interest and advice of Prof. M. M. Haring are gratefully acknowledged.
} 
and on the high hydrogen overvoltage of mercury, which inhibits the reaction between the alkali metal and water. The standard electrode potentials of all the alkali metals have been measured by this indirect method. However, these measurements have usually involved the introduction of one or more of the uncertainties caused by the use of liquid junctions, of solutions for which the activities can only be approximated, and of unreliable reference electrodes.

The standard electrode potential of sodium in use at present depends primarily on the value at $25^{\circ} \mathrm{C}$ obtained 30 years ago by Lewis and Kraus [12] ${ }^{3}$ for the nonaqueous cell.

$$
\mathrm{Na}(\mathrm{s}) ; \mathrm{NaI} \text { (in ethylamine); } \mathrm{Na}(0.2062 \% \text { amalgam), }
$$

which they combined with a measurement on the aqueous cell

$$
\begin{gathered}
\mathrm{Na}(0.2062 \% \text { amalgam }) ; \mathrm{NaOH}(0.2 N)|\mathrm{NaCl}(0.2 N)| \\
\mathrm{KCl}(0.2 \mathrm{~N}) \mid \mathrm{KCl}(1 \mathrm{~N}), \mathrm{HgCl}(\mathrm{s}) ; \mathrm{Hg}(\mathrm{l}) .
\end{gathered}
$$

The calculation of the electrode potential from the emf of this aqueous cell involves corrections for three liquid junctions, the activity of $0.2 N$ sodium hydroxide, and the reference potential of the normal calomel electrode. Lewis and Randall [13] recalculated these corrections and obtained $2.7126 \mathrm{v}$ for the standard electrode potential of sodium with respect to the hydrogen electrode. A more recent recalculation by MacInnes [15], in which the measurement of Lewis and Kraus on the nonaqueous cell is combined with an interpolated value for the cell

$$
\mathrm{Na}(0.2062 \% \text { amalgam }) ; \mathrm{NaCl}(0.1005 \mathrm{~m}), \mathrm{HgCl}(\mathrm{s}) ; \mathrm{Hg}(\mathrm{l}) \text {, }
$$

from the work of Allmand and Polack [1], gives $2.7139 \mathrm{v}$ at $25^{\circ} \mathrm{C}$. However, Allmand and Polack place a reproducibility of only $0.001 \mathrm{~V}$ on their original measurements, and an interpolation of their results is possibly less precise.

Because of the importance of accurate values of the standard electrode potentials over a range of temperatures for thermodynamic and analytic calculations, a redetermination of some of the older values appears desirable. This paper gives the results of a redetermination of the standard electrode potential of sodium, in which liquid junctions were eliminated and a reliable reference electrode was used. $\mathrm{As}$ in the pioneer work of Lewis and Kraus, a nonaqueous and an aqueous cell were used. Dimethylamine, instead of ethylamine, was used as the solvent in the nonaqueous cell because Bent and Swift, Jr. [2], have shown that dimethylamine reacts with sodium much less readily than does ethylamine. The two cells may be represented by

and

$$
\mathrm{Na}(\mathrm{s}) ; \mathrm{NaI} \text { (in dimethylamine); } \mathrm{Na} \text { (amalgam) }
$$

$$
\mathrm{Na} \text { (amalgam); } \mathrm{NaCl}(0.05 \text { or } 0.1 \mathrm{~m}), \mathrm{AgCl}(\mathrm{s}) ; \mathrm{Ag}(\mathrm{s}) \text {. }
$$

\section{UNITS AND STANDARDS}

According to computations to be published shortly by C. S. Cragoe, of this Bureau, the value of $R T_{0}$ is $2271.16 \mathrm{abs} \mathrm{j} \mathrm{mole} \mathrm{j}^{-1}$. The value of $T_{0}$, the temperature of the ice point, is taken as $273.16^{\circ} \mathrm{K}$ [24], and

\footnotetext{
3 Figures in brackets indicate the literature references at the end of this paper.
} 
the value of $R$ is therefore $8.3144 \mathrm{abs} \mathrm{j} \mathrm{deg}^{-1}$ mole- . To obtain the value of $R$ in international joules, the conversion factor of 1.00020 was accepted from the critical examination by Wensel [24], thus giving $R=8.3127$ int j deg ${ }^{-1} \mathrm{~mole}^{-1}$.

Wensel has also discussed the value of the faraday obtained from the silver and the iodine coulometers. The full precision of the mean value is given by $F^{\prime}=9.650 \times 10^{4}$ int coulombs.

In chemical thermodynamics, quantities of energy are often expressed in calories, even though these quantities are measured precisely in electrical units. Unfortunately, the term "calorie" by itself is not definite, since it may mean the heat capacity of water at some temperature or it may signify a unit defined arbitrarily in joules independently of the properties of water. The use of the calorie as a unit of energy thus requires the statement of a conversion factor which depends, for example, upon whether the calorie recommended by the International Union of Chemistry in 1934 [19] as 4.1833 int $\mathrm{j}$, the International Steam Table calorie of $3600 / 860 \mathrm{abs}$ j, or some other calorie is used. It would seem better to propose that the calorie be abandoned as a unit of energy and to work towards a gradual attainment of that end. In this paper the results are reported in international joules and the calorie is used only in calculations involving measurements reported in calories by other workers.

The primary reference electrode, with respect to which the values of standard electrode potentials are conventionally given, is the standard hydrogen electrode; but for the actual measurements it is usually necessary to employ a secondary reference electrode. For many determinations the silver-silver chloride electrode is an excellent secondary standard. The conditions under which it is constant and reproducible have been investigated [22,23], and its value with respect to the standard hydrogen electrode has been particularly well studied over a range of temperatures $\left(0^{\circ}\right.$ to $\left.60^{\circ} \mathrm{C}\right)$ by Harned and Ehlers [6]. A recent recalculation of their results [5] yielded values which were neither seriously nor consistently different from the original figures. For our measurements, the values of Harned and Ehlers as expressed by their equation

$$
\begin{aligned}
E^{\circ}=-0.22239+ & 6.4552 \times 10^{-4}(t-25)+3.284 \times 10^{-6}(t-25)^{2} \\
& -9.948 \times 10^{-9}(t-25)^{3}
\end{aligned}
$$

were adopted and are given in table 1.

TABLE 1.-Reference values of the standard electrode potential $E^{\circ}$ of the silver-silver chloride electrode and of the mean activity coefficient $f_{m}$ of sodium chloride

\begin{tabular}{|c|c|c|c|}
\hline$t$ & $E^{\circ}$ & $f_{m}(0.05 \mathrm{~m})$ & $f_{m}(0.01 \mathrm{~m})$ \\
\hline$\circ C$ & int $v$ & & \\
5 & -0.23391 & 0.8244 & 0.7808 \\
10 & -.23130 & .8239 & .7805 \\
15 & -.22851 & .8233 & .7800 \\
20 & -.22554 & .8224 & .7792 \\
25 & -.22239 & .8214 & .7782 \\
30 & -.21908 & .8202 & .7770 \\
35 & -.21562 & .8189 & .7756 \\
40 & -.21200 & .8175 & .7740 \\
\hline
\end{tabular}


The sign of an electrode potential may be taken as that of the hypothetical cell

$$
\text { electrode; solution } \| \mathrm{H}^{+}(\mathrm{a}=1) ; \mathrm{H}_{2}(1 \mathrm{~atm}) \text {, }
$$

considered as positive when the electrode acts spontaneously as the anode and the hydrogen electrode as the cathode. The double vertical lines indicate that liquid junctions or their effects have been eliminated. The numerical value of a standard electrode potential depends on the scale of concentration employed [14]. It is convenient and customary in work on electrode potentials to follow the convention popularized by G. N. Lewis [13] - to express concentrations in terms of formula weights of solute per $1,000 \mathrm{~g}$ of solvent. If the subscript $m$ denotes this molal concentration and the subscript $c$ denotes concentration per $1,000 \mathrm{~cm}^{3}$ of solution, the difference between the values of a standard electrode potential on the two scales is given by $E_{m}^{\circ}-E_{c}^{\circ}$ $=-\left(R T / N F^{\prime}\right) \ln d_{\circ}$, where $d_{\circ}$ is the density of the pure solvent at the given temperature and pressure. This equation may be derived in the following way.

By definition, activity is given by the equation $F=F^{\circ}+R T \ln a$. For a given mass, expressed on the two different scales of concentration, $F$ is the same while $F^{\circ}$ and $a$ are different. Thus

$$
F=\left\{\begin{array}{l}
F_{m}^{\circ}+R T \ln a_{m} \\
F_{o}^{\circ}+R T \ln a_{c}
\end{array}\right.
$$

Since $F_{m}^{\circ}$ and $F_{c}^{\circ}$ are both constants, it follows from the properties of the logarithm that the ratio $a_{m} / a_{c}=$ constant. The constant may be evaluated by the following method.

Consider a solution of density $d$ having a concentration expressed as $c$ moles of solute of molecular weight $M$ per $1,000 \mathrm{~cm}^{3}$ of solution, corresponding to a molality of $m$ moles per $1,000 \mathrm{~g}$ of solvent of density $d_{0}$. From the definition of these scales of concentration, their ratio may be expressed by the equation

$$
\frac{c}{m}=d-\frac{M c}{1,000},
$$

and since $a_{c}=f_{c} c$ and $a_{m}=f_{m} m$, where $f_{c}$ and $f_{m}$ are the corresponding activity coefficients,

$$
\frac{f_{m} a_{c}}{f_{c} a_{m}}=d-\frac{M c}{1,000}
$$

In aqueous solutions the infinitely dilute solution is chosen as the standard state, so that the activity coefficients approach unity as the concentration approaches zero. Thus eq 2 reduces to

$$
\frac{a_{c}}{a_{m}}=d_{\circ}
$$

when $m$ and $c$ become zero, since the density of the solution becomes that of the pure solvent, and this limiting case thus serves for the evaluation of the constant. 
The expression for the emf of an electrode as a function of the activity on the two scales is

from which

$$
E=E_{m}^{\circ}-\frac{R T}{N F} \ln a_{m}=E_{\mathrm{c}}^{\circ}-\frac{R T}{N F} \ln a_{c}
$$

$$
E_{m}^{\circ}-E_{c}^{\circ}=-\frac{R T}{N F} \ln \frac{a_{c}}{a_{m}} .
$$

Since the standard electrode potentials on the two scales are constants independent of any actual molalities or concentrations, the activity ratio in eq 4 must have the same value at a given temperature for all corresponding molalities and concentrations, including infinite dilution, and the value of this ratio is fixed by eq 3. Equation 4 may now be written

$$
E_{m}^{\circ}-E_{c}^{\circ}=-\frac{R T}{N F} \ln d_{\circ},
$$

to obtain the difference between the standard electrode potentials on the two scales. For aqueous solutions this difference amounts to zero at $4^{\circ}, 0.08 \mathrm{mv}$ at $25^{\circ}$, and $0.33 \mathrm{mv}$ at $50^{\circ} \mathrm{C}$.

A simple relationship between the activity coefficients on the two scales, namely,

$$
\frac{f_{m}}{f_{c}}=\frac{c}{d_{\mathrm{o}} m}
$$

results when the activities $a_{m}$ and $a_{c}$ are replaced in eq 3 by their equivalent expressions $f_{m} m$ and $f_{c} c$, respectively.

The activity coefficient of sodium chloride at $25^{\circ} \mathrm{C}$ has been determined precisely by Brown and MacInnes [3, 16]. Their values at this temperature for the molalities of 0.05 and 0.1 used in this work were taken as standard, and the values needed for the other temperatures at the same molalities were calculated with the aid of the excellent data obtained by Robinson and Gulbransen [4,20] on the relative partial molal heat contents of solutions of sodium chloride. From their data, the relative partial molal heat content $\bar{L}_{2}$ of the sodium chloride was expressed in calories as a linear function of the temperature by the equations

$$
\begin{gathered}
\bar{L}_{2}=93.97+3.256(t-25) \text { for } 0.05 \mathrm{~m}, \text { and } \\
\bar{L}_{2}=100.09+4.542(t-25) \text { for } 0.1 \mathrm{~m} .
\end{gathered}
$$

The difference between the logarithm of the activity coefficient at a particular temperature and at $25^{\circ} \mathrm{C}$ was then computed by integration of the equation

$$
\frac{d \ln f_{m}}{d T}=\frac{-\bar{L}_{2}}{2 R T^{2}}
$$

in which $f_{m}$ is the mean activity coefficient on the molality scale. The reference values of Brown and MacInnes, given on the volume concentration scale at $25^{\circ} \mathrm{C}$, were converted to the molality scale 
by eq 6 and then corrected to the other temperatures. The mean activity coefficients thus computed are given in columns 3 and 4 of table 1 .

\section{MATERIALS}

The mercury used in the preparation of the amalgam was virgin mercury purified by washing with nitric acid, distilling in a Hulett still [7], distilling under a vacuum, and filtering through a fritted glass filter.

The amalgam was made electrolytically in a roundbottom 1-liter flask having two sidearms for the electrodes, and at the bottom an outlet tube with a stopcock and a ground joint of standard taper, as shown in figure 1. Approximately $200 \mathrm{ml}$ of mercury was put in the flask, $A$, and covered with $400 \mathrm{ml}$ of a 5 -percent solution of sodium hydroxide, which was tested and found to conform to the specifications of the American Chemical Society for the reagent grade of this material [8]. One of the platinum electrodes dipped into the mercury and the other into the solution. The mercury was stirred mechanically during the electrolysis, which was continued until a plot of current and time indicated that the desired approximate concentration had been attained. When its preparation was completed, the amalgam was transferred to the reservoir, $C$. To relieve strain during the transfer, a flexible spiral of glass tubing, $B$, was inserted between the flask and the reservoir. The reservoir and spiral were evacuated before the amalgam was transferred. Dry nitrogen free from oxygen was then placed, at a pressure of about $20 \mathrm{~cm}$ above atmospheric, over the amalgam. The amalgam had substantially the same appearance as pure mercury and this appearance was retained throughout the investigation. For analysis, portions of the amalgam were decomposed by water, on a steam bath to hasten the rate of reaction. The resulting solutions of sodium hydroxide

Figure 1.-Apparatus for the preparation of sodium amalgam.

$A$, electrolysis vessel; $B$, flexible glass spiral; $C$, amalgam storage vessel.

were separated from the mercury, treated with an excess of standardized sulfuric acid, boiled to remove carbon dioxide, and the excess acid was titrated with standard alkali using bromthymol blue as the indicator. The analyses, which are more informational than fundamental for the investigation since the concentration of the amalgam is not involved in the final electrode potential, showed that the amalgam contained $0.06514 \pm 0.00006$ percent by weight of sodium.

The sodium used for one electrode of the nonaqueous cell was a commercial product which was found by test to conform to the specifications of the American Chemical Society for the reagent grade 
of this material [10]. A sample was converted to sodium chloride and tested for potassium [9]. Within the sensitivity of the test (0.01 percent), no potassium was found. A spectrographic examination of a sample indicated only traces of impurities.

The dimethylamine for the solvent in the nonaqueous cell was prepared from dimethylamine hydrochloride of $\mathrm{cp}$ grade and sodium hydroxide of reagent grade.

The sodium iodide for the electrolyte in the nonaqueous cell was of reagent grade, recrystallized, heated to incipient fusion, and stored in a desiccator until used.

The sodium chloride for the electrolyte in the aqueous cell was of reagent grade, further purified by two precipitations with gaseous hydrogen chloride, followed by recrystallization from redistilled water and fusion in a platinum dish. A sample was shown by test [9] to contain less than 0.01 percent of potassium.

The aqueous solutions were prepared to have the desired concentrations on the molal basis (formula weights of salt per 1,000 $\mathrm{g}$ of water) by weighing the dry salt and the added redistilled water. All weights were corrected for air buoyancy.

The nitrogen used for an inert atmosphere was freed from oxygen and other undesirable gases by passage over hot reduced copper and through columns containing dilute alkali and dilute acid. That which was used in contact with the amalgam and in the preliminary sweeping out of the cell was dried with anhydrous magnesium perchlorate, and that used to eliminate oxygen from the solution was bubbled through a solution of the same concentration.

The silver-silver chloride electrodes were of the thermal-electrolytic type and were equilibrated [22,23] in the cell for at least 2 days before use. Two of these electrodes were used in the aqueous cell and their differences in emf were always less than $0.01 \mathrm{mv}$.

\section{APPARATUS AND PROCEDURE}

The nonaqueous cell, $H$, and the apparatus for filling it are represented in figure 2. The auxiliary apparatus consisted of a still, $A$, a drying tube, $B$, filled with Drierite (anhydrous calcium sulfate), a drying tube, $C$, filled with Hydralo (anhydrous aluminum oxide), and an amine reservoir, $D$. At $E$ was placed a magnetic hammer by means of which the capillary inner seal, $I$, could be broken when desired. The bottom of one limb of the cell was fitted with a standard-taper joint to accommodate the amalgam reservoir; and the other limb was fitted with a capillary tube sealed to a bulb, from which the sodium for one electrode was later filtered into the cell through the capillary. The horizontal connecting arm of the two limbs was provided with a pocket and a tube through which the electrolyte, sodium iodide, was placed in the cell. A tube for introducing the solvent was also provided. Platinum wires for contact with the electrodes were sealed in soft glass tubes, which in turn were joined to the cell by means of graded soft glass to Pyrex seals.

One hundred grams of dimethylamine hydrochloride was placed in the still pot, and a solution containing sodium hydroxide in excess of the amount necessary to liberate the free amine was added by means of the funnel inlet. The still pot was gently heated, and cold water 
was circulated through the condenser. Tube $G$ was open to the atmosphere at this time. Dimethylamine distilled into the receiver, $D$, which had been filled partially with shavings of metallic sodium and immersed in a cooling bath containing solid carbon dioxide in a mixture of carbon tetrachloride and chloroform. When distillation was completed, the receiver was sealed off at $F$. Tube $G$ was then connected to a vacuum system and the source of pure dry nitrogen. Residual air in the receiver was removed by alternate evacuation and admission of nitrogen, after which the receiver was sealed at $G$ under

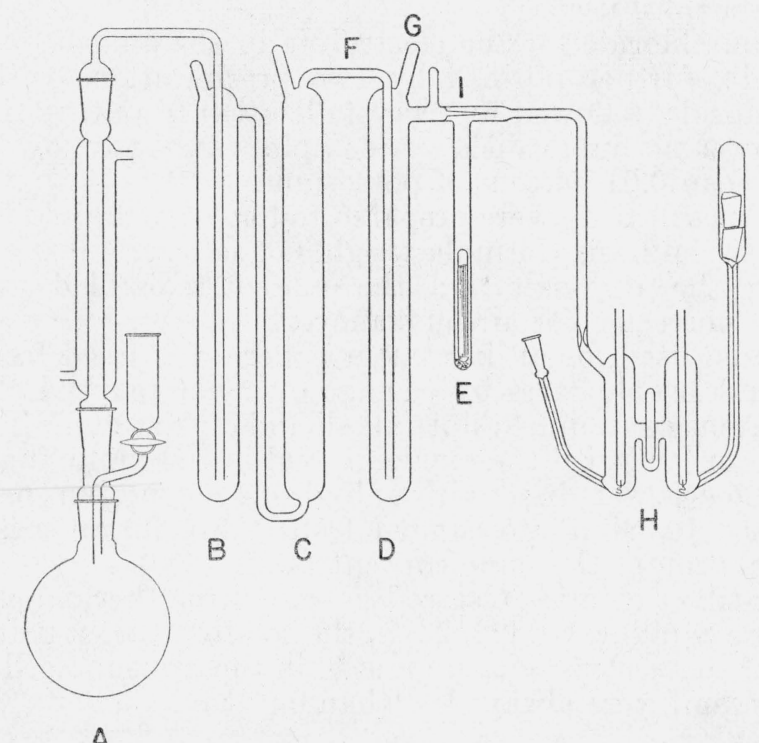

Figure 2.-Nonaqueous cell and auxiliary apparatus.

$A$, distilling assembly; $B$, drying tube containing Drierite; $C$, drying tube containing Hydralo; $D$, amine storage vessel; $E$, magnetic hammer; $H$, nonaqueous cell in position for filling; $I$, capillary inner-seal valve.

the vapor pressure of the dimethylamine at the temperature of the cooling bath. The liquid amine was thus stored over sodium until needed.

The amalgam reservoir was next connected to the cell by means of the standard-taper joint, sodium was placed in the bulb provided for it, and the sodium iodide was added. The apparatus was evacuated, a sufficient quantity of amalgam was introduced, and the side arm leading to the amalgam reservoir was sealed off close to its limb of the cell. The bulb containing the sodium was heated and the liquid metal flowed through the capillary to the other cell limb and, at the same time, was filtered from oxide crust. This side arm was then sealed off. After this, the cell was surrounded by the cooling bath, the capillary inner seal, I, was broken, and dimethylamine was distilled into the cell. When sufficient amine had been introduced, the cell was sealed off from the filling apparatus.

The main requirements upon which the design of the aqueous cell was based are (1) an easily renewable amalgam electrode to present a reproducible and unpolarized surface for each measurement; (2) a 
means for removal of used amalgam to prevent continuous reaction with the solution; (3) a means for renewal of the electrolyte to eliminate solution which has reacted with amalgam; and (4) the exclusion of oxygen.

The design adopted for the aqueous cell is shown in figure 3 . The cell proper, $G$, consisted of a longer limb for the capillary amalgam electrode and a shorter one for the silver-silver chloride electrodes.

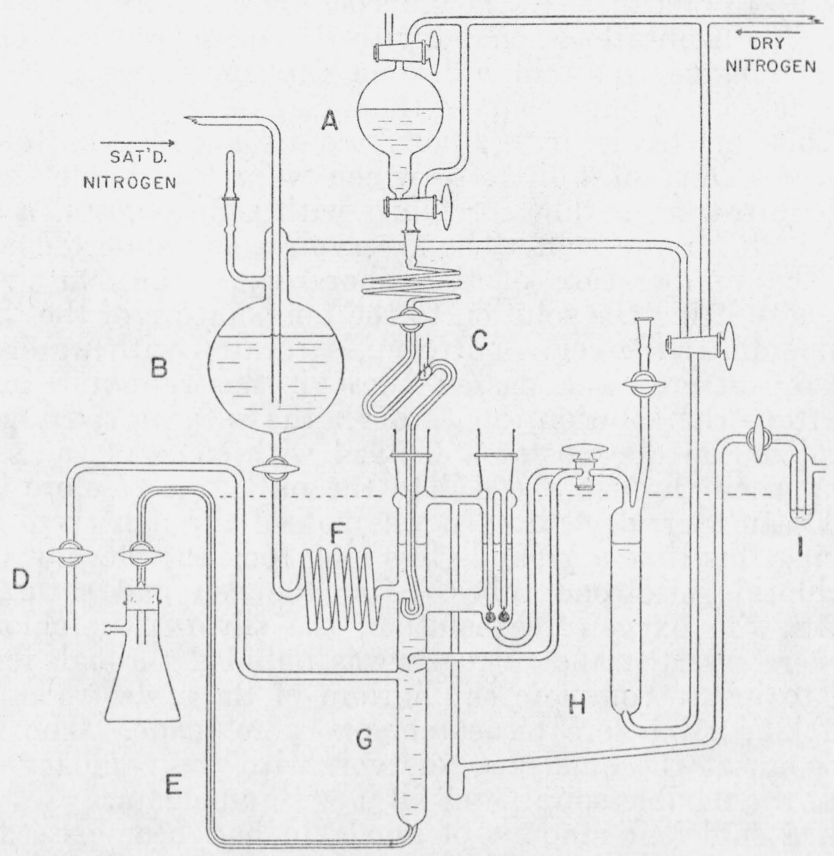

Figure 3.-Aqueous cell and auxiliary apparatus.

$A$, amalgam storage vessel; $B$, solution reservoir; $C$, capillary amalgam electrode; $D$, solution outlet tube; $E$, amalgam removal tube; $F$, solution inlet tube; $G$, aqueous cell; $H$, nitrogen gas saturator; $I$, nitrogen outlet.The dotted line shows the depth of immersion in the constant temperature bath.

The electrode tubes were sealed to ground joints of standard taper. The apparatus was made of Pyrex glass except for graded soft glass to Pyrex seals ${ }^{4}$ on the two silver-silver chloride electrode tubes, which facilitated sealing in the platinum wires to hold these electrodes. Each limb contained a gas-bubbling tube so that nitrogen could be passed through either at will. The gas outlet, $I$, common to both limbs, was provided with a sump to prevent condensed water vapor from returning to the cell when measurements were made at temperatures above that of the laboratory. The longer limb had a funnelshaped partition just below the bubble tube. A small orifice in this partition permitted drops of used amalgam to fall to the bottom and hindered back-diffusion of amalgam decomposition products. An outlet tube, $D$, just below this partition, for removing solution, and a capillary tube, $E$, for withdrawing used amalgam from the bottom, were sealed to the amalgam limb.

\footnotetext{
4 One of the intermediate glasses in these graded seals was found to be attacked by solutions of sodium chloride. The amount of decomposition was great enough to cause mechanical failure in a relatively short time and, for this reason, the graded seals were placed above the level of the solution in the cell.
} 
The capillary amalgam electrode was given an S-turn, $C$, because with a straight capillary tube a break and consequent gap in the column of amalgam sometimes occurred at the contact wire. The upward flow of amalgam past the contact wire eliminated this annoyance. To insure further against a break in the column of amalgam and to avoid preliminary contact and reaction of the amalgam with the solution, the capillary was first filled, by suction, with pure mercury up to and through the stopcock bore, before it was placed in the cell. To facilitate alinement with the amalgam reservoir, $A$, and to take up changes in strain, a flexible glass spiral was sealed between the stopcock and ground joint of the amalgam electrode.

The solution reservoir, $B$, consisted of a round-bottomed flask having a capacity of 1 liter, to which were sealed inlet and outlet tubes for nitrogen, a tube for filling with solution, and a spiral, $F$, connecting it to the cell. The reservoir was supported above the cell at the temperature of the laboratory. The function of the spiral was to bring the solution to the temperature of the thermostat before it entered the cell. Nitrogen, saturated with water vapor at room temperature, was passed through the reservoir to displace oxygen from the solution, on through the saturator, $H$, which was immersed in the thermostat and filled with some of the same solution, and then through the cell to the outlet, $I$. Before filling the cell and saturator, dry nitrogen was passed through them overnight and during this time a ground-glass plug took the place of the silversilver chloride electrode tube. After the cell and saturator were filled with the oxygen-free solution, the silver-silver chloride electrodes were inserted and nitrogen was bubbled through for at least 2 days, to insure complete equilibrium of these electrodes with the solution $[22,23]$ before measurements were made. The next step was to connect the amalgam reservoir with the capillary electrode, evacuate the flexible spiral, and fill it with amalgam.

When a sufficient amount of amalgam had been passed through the capillary to displace the pure mercury, reproducible potential differences were obtained. During the measurements, fresh solution was passed through the amalgam limb of the cell at a rate of about $2 \mathrm{ml}$ per minute. With this rate of flow, no significant differences were observed in the potentials of successive drops of amalgam, which would result if any appreciable change in composition of the solution were caused by reaction with the amalgam. To make sure of this, the amalgam limb was occasionally drained and refilled with fresh solution without causing any appreciable change in emf.

To bring the measured emf within the range of the potentiometer, an unsaturated Weston standard cell was connected in opposition to the aqueous cell, and the difference in emf was observed. This unsaturated standard cell was kept in an insulated box, and its emf was determined before and after each series of measurements.

Stationary and flowing amalgams were tried and the former proved to be more satisfactory. A fresh drop of amalgam was produced on the electrode tip and emf readings were made. The readings quickly reached a maximum which was within less than $0.1 \mathrm{mv}$ of the initial value, then varied only a few hundredths of a millivolt from this value for a longer period of about 1 minute, after which a slow but definite decrease in emf occurred. Each fresh droplet behaved in the same manner, and the maximum reading of each was recorded. 
The emf reported at each temperature is the average of at least 10 such readings, with an average deviation of about $\pm 0.02 \mathrm{mv}$. After each series of measurements was completed, the solution level was lowered so that the capillary tip was out of the electrolyte but the silver-silver chloride electrodes were still immersed in the solution. This was done to minimize reaction with the amalgam during the periods between observations. The old electrolyte was drained and fresh was run in before each new series of measurements.

Both the aqueous and nonaqueous cells were immersed in an oil thermostat which was equipped with a cooling unit for maintaining temperatures below that of the room to a constancy of $\pm 0.03^{\circ} \mathrm{C}$. For temperatures above that of the room, the constancy was better than $\pm 0.01^{\circ} \mathrm{C}$. The temperatures were read with a Beckmann thermometer, the setting of which was checked at each temperature with a platinum resistance thermometer.

The measurements of electromotive force were made with a calibrated Rubicon type $B$ potentiometer, and a pair of saturated Weston standard cells which were kindly made, calibrated, and supplied by G. W. Vinal and L. H. Brickwedde, of the Electrical Division of this Bureau. These cells were housed in a temperature-control box especially designed for saturated standard cells [18]. The galvanometer employed was a Leeds \& Northrup Type $R$ instrument which had a resistance of $495 \mathrm{ohms}$ and a current sensitivity of 0.000092 $(\mu a / \mathrm{mm}) / \mathrm{m}$.

On any one day, measurements were made at only one temperature. The first measurements were made at $25^{\circ} \mathrm{C}$ and, as soon as these were completed, the temperature of the bath was lowered to approximately $20^{\circ} \mathrm{C}$. On the following day the temperature was adjusted closely to $20^{\circ} \mathrm{C}$. Thus the temperature was within a few tenths of a degree of the desired value for at least 18 hours, and within a few hundredths for at least 2 hours, before observations were started. This procedure was continued for successive 5-degree intervals down to $5^{\circ} \mathrm{C}$. Following the measurements at $5^{\circ} \mathrm{C}$ the temperature was brought back to $25^{\circ} \mathrm{C}$ in one step for a test of reproducibility and hysteresis. The reproducibility was within a few hundredths of a millivolt, and no hysteresis effects were observed. The temperature was then raised in 5-degree steps up to $40^{\circ} \mathrm{C}$ and brought back in one step from $40^{\circ}$ to $25^{\circ} \mathrm{C}$. This procedure was applied to both the nonaqueous and the aqueous cells. Two concentrations of the solution of sodium chloride, 0.05 and $0.1 \mathrm{~m}$, and one concentration of the amalgam, 0.0651 percent by weight of sodium, were used.

\section{RESULTS AND DISCUSSION}

Nonaqueous cell.

The measured values of the emf of the nonaqueous cell,

$$
\mathrm{Na}(\mathrm{s}) ; \mathrm{NaI} \text { (in dimethylamine); } \mathrm{Na}(0.0651 \% \text { amalgam), }
$$

at the different temperatures are given in column 2 of table 2 . The results can be expressed by the equation

$$
E=0.88578+0.00008390(t-25)+0.000000762(t-25)^{2},
$$

with average and greatest deviations of 0.02 and $0.06 \mathrm{mv}$, respectively. 
The values of $\Delta \bar{F}$ in the third column were calculated from this equation and the relationship $\Delta \bar{F}=-F E$, in which $\Delta \bar{F}$ is the change in partial molal free energy accompanying the cell reaction and $F$ is the faraday. The values of $\Delta \bar{S}$, the change in partial molal entropy, given in the fourth column were obtained from the relationship $\Delta \bar{S}=F d E / d T$, in which $d E / d T=0.0008390+0.000001524(t-25)$. The values of $\Delta \bar{H}$, the change in partial molal heat content, listed in the fifth column were calculated from the equation $\Delta \bar{H}=\Delta \bar{F}+T \Delta \bar{S}$. Bent and Swift, Jr., [2] have measured similar cells and have given equations for computing $\Delta \bar{F}$ and $\Delta \bar{H}$ for different mole fractions of sodium in sodium amalgam, at different temperatures between $5^{\circ}$ and $25^{\circ} \mathrm{C}$. The values of $\Delta \bar{F}$ computed from their equations agree with ours to 0.06 percent in the comparable range of $5^{\circ}$ to $25^{\circ} \mathrm{C}$. The values of $\Delta \bar{S}$, which depend on the temperature coefficient of emf, differ by 5 to 6 percent, and the values of $\Delta \bar{H}$ differ by about 0.2 percent. Considering the small magnitude of $\Delta \bar{S}$ and that the comparison is made with interpolated data, the agreement appears adequate.

\section{TABLE 2.-Cell: $\mathrm{Na}(\mathrm{s})$; $\mathrm{NaI}$ in $\left(\mathrm{CH}_{3}\right)_{2} \mathrm{NH} ; \mathrm{Na}(0.0651 \%$ amalgam $)$ Reaction: $\mathrm{Na}(\mathrm{s})=\mathrm{Na}(0.0651 \%$ amalgam $)$}

\begin{tabular}{|c|c|c|c|c|}
\hline$t$ & $E$ & $\Delta \bar{F}$ & $\Delta \bar{S}$ & $\Delta \bar{H}$ \\
\hline & & & & \\
${ }^{\circ} C$ & int $v$ & int j/mole & int $j /$ mole deg & int $j /$ mole \\
5 & 0.88442 & -85343 & 5.16 & -83909 \\
10 & .88467 & -85372 & 5.89 & -83703 \\
15 & .88500 & -85403 & 6.63 & -83494 \\
20 & .88537 & -85438 & 7.36 & -83280 \\
25 & .88577 & -85477 & 8.10 & -83063 \\
30 & .88626 & -85517 & 8.83 & -82840 \\
35 & .88667 & -85566 & 9.57 & -82617 \\
40 & .88720 & -85615 & 10.30 & -82389 \\
& & & & \\
\hline
\end{tabular}

The effect of pressure on the emf of the nonaqueous cell was calculated to be approximately $0.008 \mathrm{mv}$ per atmosphere by the equation $d E / d P=-\Delta \bar{V} / F$, in which $\Delta \bar{V}$ is the difference between the partial molal volume of sodium in the amalgam and of pure sodium. The partial molal volume of sodium in the amalgam was estimated from the data of Maey [17]. The pressure within the cell at the different temperatures was calculated from determinations by Simon and Huter [21] of the vapor pressure of dimethylamine. The calculated corrections ranged from less than $0.01 \mathrm{mv}$ to a maximum of only 0.02 $\mathrm{mv}$ and were not applied to the data.

Aqueous cells.

The results with the aqueous cells are given in table 3 . The $E^{\circ}$ values were obtained by adding to the $E$ values the terms

$$
(R T / F) \ln \left(f_{m} m\right),
$$

in which $f_{m}$ is the activity coefficient on the molal scale, given in table 1. As a test of the reliability of the observations, the ratios of the activity coefficients were calculated by the equation $F \Delta E=2 R T \ln \left(2 f_{0.1} / f_{0.05}\right)$, in which $\Delta E$ is the difference between 
the emf of the two aqueous cells and corresponds to the transfer $\mathrm{NaCl}(0.1 \mathrm{~m})=\mathrm{NaCl}(0.05 \mathrm{~m})$. The calculated ratios were compared with the ratios of the values given in table 1 , which were used in the computations of $E^{\circ}$. Over the entire temperature range the greatest difference found between these two sets of ratios was 4 parts and the average difference was 2 parts in 1,000 . This agreement is satisfactory, since the differences in emf were obtained indirectly as the differences between quantities nearly 100 times as large. However, these differences in emf are not of sufficient accuracy to justify their use for calculations of the changes in entropy and heat content accompanying the transfer of sodium chloride between the two concentrations.

TABLE 3.-Cell: $\mathrm{Na}(0.0651 \%$ amalgam); $\mathrm{NaCl}(0.05$ or $0.1 \mathrm{~m}), \mathrm{AgCl}(\mathrm{s}) ; \mathrm{Ag}(\mathrm{s})$ Reaction: $\mathrm{Na}(0.0651 \%$ amalgam $)+\mathrm{AgCl}(\mathrm{s})=\mathrm{NaCl}(0.05$ or $0.1 \mathrm{~m})+$ $\operatorname{Ag}(\mathrm{s})$

\begin{tabular}{|c|c|c|c|c|c|c|c|}
\hline$t$ & $\stackrel{E}{E=0.05}$ & $\frac{2 \mathrm{RT}}{F} \ln \left(0.05 f_{m}\right)$ & $\begin{array}{c}E^{\circ} \\
m=0.05\end{array}$ & $\underset{m=0.1}{E}$ & $\frac{2 \mathrm{RT}}{F} \ln \left(0.1 f_{m}\right)$ & $\begin{array}{c}E^{\circ} \\
m=0.1\end{array}$ & Avg. $E^{\circ}$ \\
\hline $\begin{array}{l}{ }^{\circ} C \\
5 \\
10 \\
15 \\
20 \\
25 \\
30 \\
35 \\
40\end{array}$ & $\begin{aligned} & \text { int } v \\
& 2.20084 \\
& 2.20440 \\
& 2.20775 \\
& 2.21086 \\
& 2.21382 \\
& 2.21669 \\
& 2.21943 \\
& 2.22196\end{aligned}$ & $\begin{array}{c}\text { int } v \\
-0.15282 \\
-.15560 \\
-.15838 \\
-.16118 \\
-.16399 \\
-.16682 \\
-.16965 \\
-.17250\end{array}$ & $\begin{array}{c}\text { int v } \\
2.04802 \\
2.04880 \\
2.04937 \\
2.04968 \\
2.04983 \\
2.04987 \\
2.04978 \\
2.04946\end{array}$ & $\begin{array}{l}\text { int } ~ \\
2.17009 \\
2.17304 \\
2.17586 \\
2.17850 \\
2.18105 \\
2.18337 \\
2.18548 \\
2.18757\end{array}$ & $\begin{array}{c}\text { int v } \\
-0.12220 \\
-.12442 \\
-.12665 \\
-.12890 \\
-.13116 \\
-.13344 \\
-.13574 \\
-.13805\end{array}$ & $\begin{array}{c}\text { int v } \\
2.04789 \\
2.04862 \\
2.04921 \\
2.04960 \\
2.04989 \\
2.04993 \\
2.04974 \\
2.04952\end{array}$ & $\begin{array}{c}\text { int } \boldsymbol{r} \\
2.04796 \\
2.04871 \\
2.04929 \\
2.04964 \\
2.04986 \\
2.04990 \\
2.04976 \\
2.04949\end{array}$ \\
\hline
\end{tabular}

Combinations of cells.-By adding to each $E$ given in table 3 , the $E$ of the nonaqueous cell at the same temperature, as given in table 2 , the emf of the cell

$$
\mathrm{Na}(\mathrm{s}) ; \mathrm{NaCl}(0.05 \text { or } 0.1 \mathrm{~m}), \mathrm{AgCl}(\mathrm{s}) ; \mathrm{Ag}(\mathrm{s})
$$

is obtained for each temperature and may be expressed by the following equations.

For $m=0.05$,

$$
E=3.09964+0.0006699(t-25)-0.00000240(t-25)^{2}
$$

with average and greatest deviations of 0.02 and $0.05 \mathrm{mv}$.

For $m=0.1$,

$$
E=3.06679+0.0005671(t-25)-0.00000241(t-25)^{2}
$$

with average and greatest deviations of 0.03 and $0.07 \mathrm{mv}$.

A rather severe test of the data may be made by taking the second derivatives of these equations to calculate the difference between the molal heat capacities of the products and reactants of the cell reaction

$$
\mathrm{Na}(\mathrm{s})+\mathrm{AgCl}(\mathrm{s})=\mathrm{NaCl}(0.05 \text { or } 0.1 \mathrm{~m})+\mathrm{Ag}(\mathrm{s})
$$

by means of the relationship $\Delta \bar{C}_{p}=T F d^{2} E / d T^{2}$. The value thus found may be compared with the algebraic sum of the molal heat capacities directly observed, since

$$
\Delta \bar{C}_{p}=\bar{C}_{p}\left(\mathrm{Ag}+\bar{C}_{p}(\mathrm{NaCl}, 0.05 \text { or } 0.1 m)-\bar{C}_{p}(\mathrm{Na})-\bar{C}_{p}(\mathrm{AgCl})\right.
$$


At $25^{\circ} \mathrm{C}$ and $m=0.05$, for example, $\Delta \bar{C}_{p}$ is calculated from the equation involving the second derivatives of $E$ to be -138 int $j$ as compared with -133 for the sum of the separately measured quantities. A more interesting comparison is that of the value calculated for $\overline{C_{p}}(\mathrm{NaCl}$, 0.05 or $0.1 \mathrm{~m}$ ) with its value obtained from measurements of heats of dilution. Thus, from the values of $\bar{C}_{p}$ for silver (25.3), sodium (28.4), and silver chloride (52.6), listed in International Critical Tables [11], and our result of -138 int $\mathrm{j}$ for $\Delta \bar{C}_{p}$, the partial molal heat capacity of $0.05 \mathrm{~m}$ sodium chloride is calculated to be -82.3 int $\mathrm{j}$ or $-19.7 \mathrm{cal}$. Gulbransen and Robinson [4], from measurements on the heats of dilution of solutions of sodium chloride, expressed its partial molal heat capacity in calories by the equation $\bar{C}_{p}=-21.9+15.8 \mathrm{~m}^{1 / 2}$, which yields - 18.4 calories for $0.05 \mathrm{~m}$ with a probable error which they estimate to be not more than 15 percent. The agreement at $0.1 \mathrm{~m}$ is not quite as close, the difference being $2.9 \mathrm{cal}$, but is satisfactory for a comparison which involves a second derivative and data on specific heats from various sources.

For the cell

$$
\mathrm{Na}(\mathrm{s}) ; \mathrm{NaCl}\left(f_{m} m=1\right), \mathrm{AgCl}(\mathrm{s}) ; \mathrm{Ag}(\mathrm{s})
$$

the value of $E^{\circ}$ at each temperature was obtained by adding to each average $E^{\circ}$ for the aqueous cell, given in the last column of table 3, the corresponding $E$ for the nonaqueous cell given in table 2. The results, which are given in table 4, may be expressed by the equation

$$
E^{\circ}=2.93564+0.0001096(t-25)-0.00000268(t-25)^{2},
$$

which shows an average deviation of $0.02 \mathrm{mv}$ and a greatest deviation of $0.04 \mathrm{mv}$ from the tabulated results. Table 4 also includes the change in partial molal free energy, entropy, and heat content accompanying the cell reaction, calculated with the aid of the equation and its first derivative.

$$
\begin{array}{r}
\text { TABLE 4.-Cell: } \mathrm{Na}(\mathrm{s}) ; \mathrm{NaCl}\left(f_{m} m=1\right), \mathrm{AgCl}(\mathrm{s}) ; \mathrm{Ag}(\mathrm{s}) \\
\text { Reaction: } \mathrm{Na}(\mathrm{s})+\mathrm{AgCl}(\mathrm{s})=\mathrm{NaCl}\left(f_{m} m=1\right)+\mathrm{Ag}(\mathrm{s})
\end{array}
$$

\begin{tabular}{|c|c|c|c|c|}
\hline \multicolumn{1}{|c|}{$t$} & $E^{\circ}$ & $\Delta F^{\circ}$ & $\Delta S^{\circ}$ & $\Delta H^{\circ}$ \\
\cline { 1 - 4 }${ }^{\circ} C$ & int $v$ & int $j /$ mole & int $j /$ mole deg & int j/mole \\
5 & 2.93238 & -282975 & 20.9 & -277156 \\
10 & 2.93338 & -283072 & 18.3 & -277879 \\
15 & 2.93429 & -283159 & 15.8 & -278619 \\
20 & 2.93501 & -283229 & 13.2 & -279369 \\
25 & 2.93563 & -283289 & 10.6 & -280134 \\
30 & 2.93616 & -283336 & 8.0 & -280914 \\
35 & 2.93643 & -283369 & 5.4 & -281702 \\
40 & 2.93669 & -283390 & 2.8 & -282507 \\
\hline
\end{tabular}

The standard electrode potential of sodium.-The emf of the hypothetical cell

$$
\mathrm{Na}(\mathrm{s}) ; \mathrm{Na}^{+}\left(f_{m} m=1\right) \|_{\ell} \mathrm{H}^{+}\left(f_{m} m=1\right) ; \mathrm{H}_{2}(1 \mathrm{~atm})
$$


may be found by adding the standard electrode potential of the silver-silver chloride electrode, given in table 1 , to the electrode potential of the cell

$$
\mathrm{Na}(\mathrm{s}) ; \mathrm{NaCl}\left(f_{m} m=1\right), \mathrm{AgCl}(\mathrm{s}) ; \mathrm{Ag}(\mathrm{s})
$$

given in table 4 , at each temperature. The $E^{\circ}$ value thus obtained at each temperature is the standard electrode potential of sodium. These final results are shown in table 5 together with the value of $E^{\circ}$, $\Delta F^{\circ}, \Delta S^{\circ}$, and $\Delta H^{\circ}$ calculated from the equation

$$
E^{\circ}=2.71324+0.0007532(t-25)+0.000000688(t-25) .^{2}
$$

This equation expresses the tabulated values of the standard potential of sodium in the temperature range of $5^{\circ}$ to $40^{\circ} \mathrm{C}$, with an average deviation of 0.02 and a greatest deviation of $0.05 \mathrm{mv}$. The smoothed values of $E^{\circ}$, calculated from the equation and given in column 3 of table 5, are recommended as "best" values for the standard electrode potential.

\begin{tabular}{|c|c|c|c|c|c|}
\hline$t$ & $\begin{array}{c}E^{\circ} \text { from } \\
\text { measurements }\end{array}$ & $\begin{array}{l}E^{\circ} \text { from } \\
\text { equation }\end{array}$ & $\Delta F^{\circ}$ & $\Delta S^{\circ}$ & $\Delta H^{\circ}$ \\
\hline $\begin{array}{r}{ }^{\circ} C \\
5 \\
10 \\
15 \\
20 \\
25 \\
30 \\
35 \\
40\end{array}$ & $\begin{array}{c}\text { int v } \\
2.69847 \\
2.70208 \\
2.70578 \\
2.70947 \\
2.71324 \\
2.71708 \\
2.72082 \\
2.72469\end{array}$ & $\begin{array}{c}\text { int v } \\
2.69846 \\
2.70206 \\
2.70578 \\
2.70949 \\
2.71324 \\
2.71703 \\
2.72084 \\
2.72466\end{array}$ & $\begin{array}{c}\text { int } j / \text { mole } \\
-260401 \\
-260749 \\
-261108 \\
-261466 \\
-261828 \\
-262193 \\
-262561 \\
-262930\end{array}$ & $\begin{array}{c}\text { int j/mole deg } \\
70.0 \\
70.7 \\
71.4 \\
72.0 \\
72.7 \\
73.4 \\
74.0 \\
74.7\end{array}$ & $\begin{array}{c}\text { int } j / \text { mole } \\
-240921 \\
-240732 \\
-240545 \\
-240353 \\
-240155 \\
-239956 \\
-239754 \\
-239543\end{array}$ \\
\hline
\end{tabular}

TABLE 5.-The standard electrode potential of the sodium electrode

The accuracy of the final results depends on a number of factors. Leaving out of consideration, for the moment, the reference silversilver chloride electrode, the most critical of these factors and the calculated influence of their estimated uncertainties are:

(1) The activity coefficients of sodium chloride, including their corrections to the different temperatures $(0.03 \mathrm{mv})$.

(2) Accuracy and constancy of temperatures $(0.01 \mathrm{mv})$.

(3) Polarization of the amalgam electrode in the aqueous solution (0.02 mv).

(4) Calibrations of potentiometer and standard cells $(0.02 \mathrm{mv})$.

(5) The concentrations of the aqueous solutions $(0.005 \mathrm{mv})$.

(6) Accidental errors $(0.01 \mathrm{mv})$.

(7) Neglect of pressure corrections $(0.00$ to $0.02 \mathrm{mv})$.

The square root of the sum of the squares of these errors gives 0.04 to $0.05 \mathrm{mv}$ for an estimate of the over-all accuracy of the measurements. The reference values of the silver-silver chloride electrode are probably good to about the same amount, so that the values obtained for the standard electrode potential of the sodium electrode are considered to be correct to within $0.1 \mathrm{mv}$. 


\section{REFERENCES}

[1] A. J. Allmand and W. G. Pollack, J. Chem. Soc. 115, 1020 (1919).

$[2]$ H. E. Bent and E. Swift, Jr., J. Am. Chem. Soc. 58, 2216 (1936).

[3] A. S. Brown and D. A. MacInnes, J. Am. Chem. Soc. 5\%, 1356 (1935).

[4] E. A. Gulbransen and A. L. Robinson, J. Am. Chem. Soc. 56, 2637 (1934).

[5] W. J. Hamer, J. O. Burton, and S. F. Acree, J. Research NBS 24, 269 (1940) RP1284.

[6] H. S. Harned and R. W. Ehlers, J. Am. Chem. Soc. 55, 2183 (1933).

[7] G. A. Hulett, Phys. Rev. 33, 312 (1911).

[8] Ind. Eng. Chem. 1\%, 756 (1925); 18, 636 (1926).

[9] Ind. Eng. Chem. 20, 979 (1928).

[10] Ind. Eng. Chem. Anal. Ed. 2, 351 (1930).

[11] Int. Crit. Tables 5, 85--97 (1929).

[12] G. N. Lewis and C. A. Kraus, J. Am. Chem. Soc. 32, 1459 (1910).

[13] G. N. Lewis and M. Randall, Thermodynamics, p. 33 and 416 (McGrawHill Book Co., Inc., New York, N. Y., 1923).

[14] A. Macfarlane and O. Gatty, Phil. Mag. [7] 13, 283, 291 (1932).

[15] D. A. MacInnes, Principles of Electrochemistry, p. 197 (Reinhold Publishing Corporation, New York, N. Y., 1939).

[16] D. A. MacInnes and A. S. Brown, Chem. Rev. 18, 335 (1936).

[17] E. Maey, Z. physik. Chem. 29, 119 (1899).

[18] E. F. Mueller and H. F. Stimson, J. Research NBS 13, 699 (1934) RP 739.

[19] Premier Rapport de la Commission Permanente de Thermochimie, International Union of Chemistry, p. 3 (1934).

[20] A. L. Robinson, J. Am. Chem. Soc. 54, 1311 (1932).

[21] A. Simon and J. Huter, Z. Elektrochem. 41, 28 (1935).

[22] E. R. Smith and J. K. Taylor, J. Research NBS 20, 837 (1938) RP 1108.

[23] J. K. Taylor and E. R. Smith, J. Research NBS 22, 307 (1939) RP 1183.

[24] H. T. Wensel, J. Research NBS. 22, 375 (1939) RP 1189.

Washington, September 20, 1940. 